\title{
Ethnic Cultural Identity Crisis and Its Adaptation-Taking Blang Ethnic Group in Yunnan Province as an Example
}

\author{
Xi Chunai ${ }^{1}$, Li Qin ${ }^{2}, \quad$ Zhang Yinzhu ${ }^{3}$ \\ 1 School of Public Management, Yunnan University of Economics and Finance, Kunming, P.R. \\ China, 650221 \\ 2 Faculty of Applied Foreign Languages Studies, Yunnan University of Economics and Finance, \\ Kunming, P.R. China, 650221 \\ 3 Law School, Yunnan University of Economics and Finance, Kunming, P.R. China, 650221 \\ (Email:xixi1972@126.com, liqin01@189.cn, yzh16702@126.com)
}

\begin{abstract}
With the increasing development of globalization, the Blang ethnic group like most of other ethnic minority groups in the world is also facing the impact coming from non-native cultures. According to questionnaires and interviews the authors carried out, this study shows that the Blang ethnic minority group, which is one of the ethnic groups with less population in China, is confronted with a serious crisis in its cultural identity. The young generation of the Blang increasingly pursues the modernization of the basic necessities, having no ability to speak their native language, ignoring the history of their own nationality, unwilling to wear traditional dress and live in the traditional houses,. Through investigation, the authors found that factors affecting the Blang cultural identity are mainly the way of life, school education and subjective consciousness, of which the last one is in fact of great significance. Based on the findings and research, the authors believe that the key of tackling the crisis is to make Blang subjective consciousness reestablish from the
\end{abstract}

"cultural inferiority" to the "cultural consciousness".

Keywords: cultural identity, Blang ethnic group, cultural identity crisis, cultural awareness

\section{Introduction}

In the context of globalization, the world's dramatic restructuring has rendered the issue of national cultural identity crisis apparently more conspicuous. Among scholars for this issue there are many expositions, one of which is made by American scholar Huntington. Huntington holds that the economic development of urbanization and globalization brings people to rethink their identity and in the meantime crisis of national identity has become a global phenomenon[1]. Besides, Chinese scholars put forward that Minority cultural identity is facing multicultural intrusion with the result of increasing declining of cultural identity[2]. The reconstruction of ethnic cultural identity should comply with the following seven 
principles: tolerance, recognition, respect, mutual benefits, responsibility, restraint and resistance [3]. The research on the connotation of school education and cultural identity is eminently significant for the adjustment of national cultural identity crisis[4].

The research findings above reveal the fact that the growing impact of globalization has made most of the ethnic minority cultures in the world suffer a severe culture shock, expressing that the diversity of survival with distinct regional characteristics is gradually passing off, traditional customs continue to be obscured by the modern culture, no successors are to learn traditional knowledge and skills. Generally speaking, the universals of the modern human culture are gradually replacing the traditional cultural diversity. Cultural identity crisis involved has thereby brought an appreciably negative influence on ethnic cultural development. Therefore, it is necessary to have positive response and adjustment of national cultural identity crisis for the cultural diversity in China as well as in the world.

\section{Cultural Identity Crisis Faced by the}

\section{Ethnic Group with Less Population}

With the impact of globalization and the main ethnic group culture, the traditional way of life of the Blang people has been moving away

\begin{tabular}{l|lr|lc|ll}
\multicolumn{2}{l}{ of the Blang people has been moving away } \\
& $\begin{array}{l}\text { Ability } \\
\text { their } \\
\text { language }\end{array}$ & $\begin{array}{r}\text { speak } \\
\text { native }\end{array}$ & $\begin{array}{l}\text { Whether to wear the ethnic } \\
\text { group costume }\end{array}$ & $\begin{array}{l}\text { Whether to know the } \\
\text { traditional culture }\end{array}$ \\
\hline Percentage & great & $8 \%$ & often & 0 & great & 0 \\
& a little & $59 \%$ & Occasionally & $63 \%$ & little & $80 \%$ \\
& never & $33 \%$ & never & $37 \%$ & never & $20 \%$ \\
\hline Total & & $100 \%$ & & $100 \%$ & & $100 \%$ \\
\hline
\end{tabular}

Table 1: The Current Situation of the Traditional Culture among the Blang Young People $(n=105)$ from the vision of the community people. Besides, their basic necessities of life are increasingly showing the characteristics of modernization.

As local officials said, now in Blang ethnic group traditional culture is facing a severe identity crisis, LXZ: "Our ethnic group is about to disappear and the culture is almost Hanized!" Now, in the Blang ethnic group communities, most of the Blang adolescents do not speak the native language, wear the ethnic group dress, and have the knowledge of the history and culture of their ethnic group. Our questionnaire (Table 1) shows that of 105 the Blang students, 37 percent of students never wear traditional dress, 59 percent of the students can only speak a little native language while 33 percent of the students never speak their native language. Those who are willing to talk with each other in Brown language at home only account for 8 percent. The students with no history of their own nationality take up 20 percent while most of the students about 80 percent of them can understand only a little through oral teaching by the seniors at home. Our interviews with several cultural heirs further confirm this situation. The Blang young people with the attitude of evasion and alienation now 
are keen to pursue the mainstream of culture instead of their own one, lacking in interest in traditional culture .

Case 1: Suohuai A, who received the title of the Folk musical heir from the government, is a skilled folk music artist. However, his two sons are not interested in folk music and left the countryside for the cities to hunt job.

Case 2: Yinmei Li, who received the title of the ethnic costume heir from the government, is skillful in sewing the Blang traditional costumes. Her daughters do not feel like traditional costumes sewing, once saying "It will usually take about three months to complete a suit of clothes, only to be valued as less as about hundreds of yuan in the market. It is so cheap and time-consuming that the youth prefer to go to the city for the job with better financial return."

Case 3: Xiaoqin Qi, a Blang woman with no ability of speaking her native language at all is married to a Han coming from other province. Owing to this situation their two-year-old daughter has consequently been brought up in a non-native language environment, knowing nothing about the Blang ethnic group language.

Language and dress are the most significant symbolic representation different from other ethnic groups. The gradual disappearance of these characterizations means that the uniqueness of the nationality will increasingly be weakened and about to disappear, finally melting into other minorities. These phenomena show that the Blang is experiencing unprecedented impact in the modern tide: With traditional culture gradually being stripped from the real life; young people are slowly unfamiliar to the culture of their own ethnic group; showing less and less identity on the ethnic group culture; intentionally or unintentionally alienating their traditional culture. All of these problems have become an important issue that we can not ignore.

\section{The Factors That Affect the Ethnic Group with Less Population Cultural Identity}

The generation and changes of the cultural identity are basically subject to many factors, not only to its living environment but also to their subjective consciousness.

\subsection{The way of life}

Just as every ethnic group is to survive and develop in the adaptation to the environment, their own cultural system and type are also established in the same environment when cultivating adaptation. "Human being as a kind of animal, like other animals, must maintain a relationship with environment in order to survive. Although human can achieve this adaptation via cultural media, but the process remains the same biocompatibility by the domination of select law."[5] The Blang traditional culture is developed when adapting to their own unique living environment.

With the changes of society, the natural environment of the Blang survival is also undergoing changes without sound, which makes the Blang constantly adjust their original culture in order to survive. The way of livelihood change is the most typical example.

The changes in the ecological environment makes the hunter-gatherer way of life gradually fade from our view and replaced by the farming culture. When agricultural production is difficult to meet the needs of some people's lives, shifting to the city has become a goal that the new generation of Blang people pursues. Nowadays in the Blang 
communities almost $2 / 3$ of the middle-aged go outside all through the year as migrant workers for better pay, leaving the aged and children alone in the village.

The situation that young adults of the Blang villages are keen to work outside the home has led to the one-way social mobility increase.

Compared with those who are stuck in their hometown, migrant workers from the Blang villages have superficially obtained more income and are practically closer to modern cultural life. But unfortunately, at least some negative consequences have been brought into being. On the one hand, the unique characteristics of the native ethnic group are gradually getting diminished and lost. On the other hand, being short of sustainable carriers of local heritage, the absence of young people makes it difficult to carry out traditional cultural activities in community, leading to a serious situation of scarcity of cultural heritage. Furthermore, because of their parents' long-term absence from home the left-behind children in the countryside rarely get nourishment of the ethnic group culture from parents when family education is ignored and weakened, which has become one of the reasons why Blang children are steadily straying away from their native history and culture.

\subsection{School education}

Education is not only an important force in intergenerational cultural preservation but also the most essential supporter in cultural identity. When transferring human knowledge accumulation, education also diffuses and disseminates other cultures, which actually brings an impact on the ethnic group culture. Thus, education plays an important role in the course of cultural identity and changes.
"The school is important with its clear and unique functions of cultivating generations. Only when children have a systematical understanding about their culture and country can they have a sense of identity for a complete personality."[6]

Our survey found that in vertical comparison, school education has indeed played a great role in imparting the mainstream culture. But from the horizontal comparison, it is not difficult to find what the vast majority of the being educated got from school has a large gap in the requirements of the mainstream society (except for a few people who can continue their studies). They can not adapt themselves to the needs of mainstream society, which best explains why "even in the city, they can only engage in the most difficult toil labor". In the transmission of ethnic minority culture, as the national education evaluation system does not cover the ethnic culture education, bilingual education carried vigorously out a few years ago in school is nothing but an empty shell, much less to spread the heritage of ethnic minority culture. Obviously, the school education in minority concentrated region rarely functions well in the transmission of cultural heritage as well as in the knowledge diffusion, which means that during nine-year compulsory education (from the age of 7 to 16) the minority students, who spend most of their time in school, can neither have a good command of modern knowledge nor learn their traditional cultural knowledge in school. When stepping out of school, they are named as a kind of" Marginal people" who drift between the two cultures. In other words, the tendency of marginalization they appear makes them into their identity crisis, unable to integrate 
into mainstream culture, and difficult to smoothly return to their local culture.

\subsection{Subjective consciousness}

Subjective consciousness is the most critical factor that impact greatly on ethnic group cultural identity. In the tide of globalization, with the changes of style in traditional production and life, many things representing ethnic culture such as traditional architecture, production, and the livelihoods nowadays are disappearing at an increasing rate.

Especially for the ethnic group with less population, because of their smaller range of cultural core and weak capacities to keep heritage, they will apparently feel more stray and slowly lose the self-expression under the impact of foreign culture. Young people generally have no confidence in their own nationality culture, instead, the foreign mainstream culture has become the chief life goal that many of them desire for. In their view, it is out of date to dwell in the local-style houses, wear traditional dress and speak their native languages. Whereas they pursue living in the Han-style house, wearing Han-style clothing, speaking Han language or Mandarin, feeling ashamed to show their own characteristics and culture of their ethnic group "This is a typical cultural inferiority!" is said by Mr. Feng, the local cultural elite, who is quite sad when referring to such a phenomenon. During the period of collecting Blang culture, he once went to the remote community of Blang and asked a handful of locals to sing folk music, but was refused at first by waving their hands "No". With $\mathrm{Mr}$ Feng's explanation and sincerity, the locals began to sing beautiful folk songs that made Mr. Feng amazed and impressed a lot. Similar phenomenon has repeatedly been found during our fieldwork. QXQ: "Now, when brides get married, they believe that both the Han-style clothing and ethnic group costumes are out of date, western wedding dress is more fashionable." LYQ: "My daughter has gone outside to work and will not come back. She thinks that her hometown is too old-fashioned". YXQ "Soon, I will go to Shanghai to work since lifestyle at home is too outdated". Influenced by the complex of ethnic group inferiority, they turn a blind eye to or intentionally drift away from the bright spot of the ethnic group culture, consequently bringing about the loss of some of the nationality's precious cultural resources. Furthermore, their ignorance of the native culture will finally lead to the emptiness of both spirit and recognition, which in modern life will practically make them lose themselves. Thus, in order to rebuild the ethnic cultural identity and eliminate their cultural inferiority, reconstruction of its cultural self-confidence is necessarily important.

\section{The Adjustment Path for the Blang Cultural Identity Crisis: from the "Cultural Inferiority" to "Cultural Consciousness"}

Cultural identity of ethnic minority group is generally affected by many factors, in which the "cultural consciousness" for the nationality is the key to solve the identity crisis. Under the present background, cultural subjects particularly with less population will go through a tortuous process of psychological rehabilitation to awaken this consciousness.

\subsection{From the "cultural inferiority" to "cultural self-confidence"}

Cultural awareness of the ethnic group subject is the inherent power of a nation's cultural development. Only when an ethnic group 
appears proud and confident in its own culture will its people have a strong sense of cultural identity with it, gain self-esteem from it and actively seek adjustment to development in cultural changes. The arousing of ethnic cultural consciousness is just what Fei Xiaotong said, namely the "cultural consciousness". With the cultural consciousness, the minority people will be able to understand the history of their own culture, to appreciate its own characteristics and advantages and to make efforts to inherit it, which sequentially make the local culture and mainstream culture harmoniously connected, greatly promoting the development of the nation's traditional culture. If the ethnic group subject does not enjoy such inherent power and needs, even with external social support, it is only yawn-provoking at best, unable to solve the problem fundamentally. The arousing of ethnic cultural consciousness should not only rely on the ethnic minority group itself, external intervention also plays a strong role in it. The survey found that the Blang in Shidian county is more confident in their ethnic group culture than the Blang in Bangxie. Whenever asked to show the singing voice or sewing skills, no one in Shidian refused. They naturally and gracefully showed the local songs with supreme confidence. However the respondents from Bangxie were somewhat coy and reserved, showing some sense of coward in their songs. One of the important reasons for the difference is that Shidian government recently has tried to create "Golden BLang" brand and establish the image of the "Golden Blang" with the intention of sparking a strong sense of identity and self-confidence of the local Blang.

\subsection{From "cultural self-confidence" to the "cultural identity"}

Cultural identity is a consensus and recognition of the ethnic group culture from cultural subjects. It is built on the basis of cultural self-confidence, Only with full confidence in the ethnic group culture can the people of ethnic group produce a sense of cultural identity and pride, Otherwise, the ethnic group cultural identity are naturally prone to crisis.

For a long time, it is precisely because of the intervention of external mainstream culture that the holders of minority cultures slowly lose confidence in their ethnic group culture, which in fact should be the responsibility of the schools. In the frontier regions, schools are the places of cultural transmission frequently exposed to the villagers. It is from the windows of schools that villagers gradually get to know the variety of the world outside. What schools teach determines the dimensions the villagers have about the outside world. Over the years, school education, pay more attention to reflecting the mainstream culture. Mainstream culture has become people's value orientation and schools' value orientation, which actually has also been valued by both students and their parents. Due to the influence of such values, in many minority schools teachers and students, when infused with main cultural content, give up and stray away from their nationality's history and unique culture, slowly developing a cultural inferiority complex. In this context, an intervention from object is particularly necessary to reconstruct the cultural self-confidence from cultural subjects. Therefore, if schools, the representatives of the main culture, can actively promote ethnic group culture, the 
public and media can intentionally show their concern and attention to the ethnic group culture, the cultural self-confidence will be better stimulated and sequentially help to build cultural identity.

\subsection{From the "cultural identity" to the "cultural consciousness"}

"Developing cultural awareness is a difficult process, only through discovering a nation's own culture, understanding and getting access to various kinds of other cultures can this nation win a place in this emerging multi-cultural world. After the self-adaptation, the nation together with other cultures will probably build a common recognition of the basic order and establish a series of rules of peaceful coexistence, mutual benefits and further development through joint efforts."[7] .It is not difficult to find that the "cultural consciousness" put by Fei Xiaotong is based on the premise of cultural self-confidence and built on the basis of cultural identity. When people are fully aware with strong sense of identity and pride that the culture of their nation is in no way inferior to other cultures, they can consciously protect, inherit and carry forward the ethnic group culture, which in turn will strengthen the sense of ethnic cultural pride, promoting the ethnic cultural identity.

\section{Conclusion}

In a sense, an emphasis on main ethnic group cultural identity is the cultural conscious reconstruction. Once with the cultural consciousness as the basis, more intrinsic power will be built to inherit native culture, and accordingly the cultural identity will at the same time have a solid foundation .On the one hand, the cultural consciousness from cultural subjectivity caused by cultural identity is the fundamental guarantee that ethnic group culture can be carried on from generation to generation, which in turn provides practical support for strengthening ethnic group cultural identity. Therefore, whether traditional cultural identity crisis can be effectively mitigated or adapted actually lies in the cultural subjectivity of consciousness. Nowadays in modern society, proper state policies as well as school education are undoubtedly an important guarantee for reconstruction of the cultural self-confidence and identity of Blang ethnic group culture.

\section{Acknowledgment}

The research for this article was sponsored by Humanities and Social Science Project of the Ministry of Education "The Educational Practice and Cultural Change of the ethnic groups with less population in Yunnan" ( No. 11YJCZH194)and by Project of Yunnan Provincial scientific research "The Change of Cultural Distribution and Educational Choices for the ethnic groups with less population "( No. 2011Y036)

\section{References}

[1] SamuelP Huntington. Who Are We? The Challenges to Americas National Identity, Simon\& Schuste Rockefeller Center, 2004, pp. 123.(In Chinese)

[2] Liu Hui. Thinking of the Guangxi Ethnic Culture Identity from the Perspective of Globalization[J].NanFangJournal. 2012.6:84-88.(In Chinese)

[3] Dai Xiaodong. Reflections on the Contemporary National Identity Crisis[J]. World Economy and Politician, 2005.5:52-58.(In Chinese) 
[4] Ren Zhihong, The Cultural Identity of Ethnic Minorities and the Educational Development of National Schools[J]. Hebei Academic Journal, 2010.6:242-244.(In Chinese)

[5] R.M. Keesing. Cultural Anthropology: a contemporary perspective [M].Translated by Gan Huaming, Shenyan, Liaoning People Publishing Press 1988.151. .(In Chinese)

[6] Durkheim, E. 1956. Education and Sociology. Trans. S. D. Fox . Glencoe: The Free Press. pp. 123 124.

[7] Fei Xiaotong. Culture and Cultural Consciousness[M]. Beijing: Qun Yan Publishing Press, 2010.195.(In Chinese) 